\title{
ANEURYSM OF AN INTERCOSTAL ARTERY AFTER PARACENTESIS THORACIS
}

\author{
BY \\ J. S. ELKINGTON AND J. B. L. HOWELL \\ From the Middlesex Hospital, London
}

(RECEIVED FOR PUBLICATION JANUARY 1, 1960)

The patient (M.H. No. K: 40916), a 14-year-old girl, was admitted to the Middlesex Hospital on July 23, 1958 , with malignant hypertension due to nephritis in early childhood. Her blood pressure on admission was $250 / 180 \mathrm{~mm}$. $\mathrm{Hg}$, but was lowered to, and maintained at, normal levels by a combination of a ganglionblocking drug ("pempidine") and "hydrallazine." This regimen was considered impracticable for longterm management in view of the severity of the sideeffects. Thoraco-lumbar sympathectomy was therefore advised.

A pre-operative aortogram was complicated by a left haemothorax. Blood and pleural fluid were aspirated from the pleural cavity on four occasions by needle puncture through the seventh and eighth intercostal spaces lateral to the angle of the ribs. Nothing unusual was noted during or immediately following these aspirations.

After the pleural fluid had absorbed, the patient was discharged to convalescence, receiving "pempidine," $27.5 \mathrm{mg}$., and " hydrallazine," $150 \mathrm{mg}$. daily in divided doses.

She was readmitted for operation three weeks later, by which time her blood pressure had risen to an average of $170 / 125 \mathrm{~mm}$. $\mathrm{Hg}$ with much variation during the day; physical examination otherwise was normal. Four days later (50 days after the first chest aspiration), a continuous " machinery" murmur was heard in a localized area of the posterior chest wall over the left eighth rib and intercostal space, the site of one of the aspirations. A phonocardiogram recorded over this area is shown in Fig. 1. The murmur could be reduced in intensity by applying pressure to the intercostal space with the bell of the stethoscope.

We thought that an arteriovenous communication between the intercostal vessels had arisen due to trauma from a needle puncture. However, this was not so. During the operation for thoraco-lumbar sympathectomy by Mr. L. P. Le Quesne the eighth intercostal space was explored and an aneurysm $(1 \mathrm{~cm}$. diameter) was found on the intercostal artery. There was no arteriovenous communication. A segment of the intercostal artery containing the aneurysm was excised. The histological report (Bland-Sutton Institute of Pathology, S.189/58), by Dr. A. D. Thomson, was as follows.
"Serial sections through the tissue show a blood
vessel at each end connected in the middle by a
fibrous-walled, blood-filled space. The appearances
of this area are consistent with a small, fibrous-
walled aneurysm."

Post-operative progress was smooth and the blood pressure level was stabilized at about $130 / 70 \mathrm{~mm}$. Hg. A renal biopsy taken at the operation showed the changes of chronic glomerulo-tubular nephritis.

\section{Discussion}

The possibility of damage to an intercostal artery during paracentesis thoracis has long been recognized. To avoid this, it is advised that aspirations be made in the intercostal space lateral to the angle of the ribs just above the lower rib. In this position the intercostal artery is protected by the costal groove of the upper rib. In our experience, the intercostal space usually feels too narrow to make accurate direction of this kind possible.

Although an intercostal artery is occasionally punctured, with subsequent haematoma formation, we have been unable to find any record of the later development of an aneurysm. In view of the frequency with which paracentesis thoracis is performed, the complication which occurred in this patient must be very rare.

The delay between the presumed injury to the arterial wall and the development of the aneurysm is of interest. It is possible that poor control of the hypertension with drugs during convalescence from the haemothorax was responsible for the eventual bulging of the weakened arterial wall.

\section{SUMMARY}

The development of an aneurysm of an intercostal artery at the site of an earlier paracentesis thoracis is repeated.

We wish to thank Dr. A. Willcox for his encouragement and advice. We also wish to thank Dr. D. E. Bedford and Professor Scarff for permission to publish these findings, and Mr. L. P. Le Quesne and Dr. A. D. Thomson for their reports. 

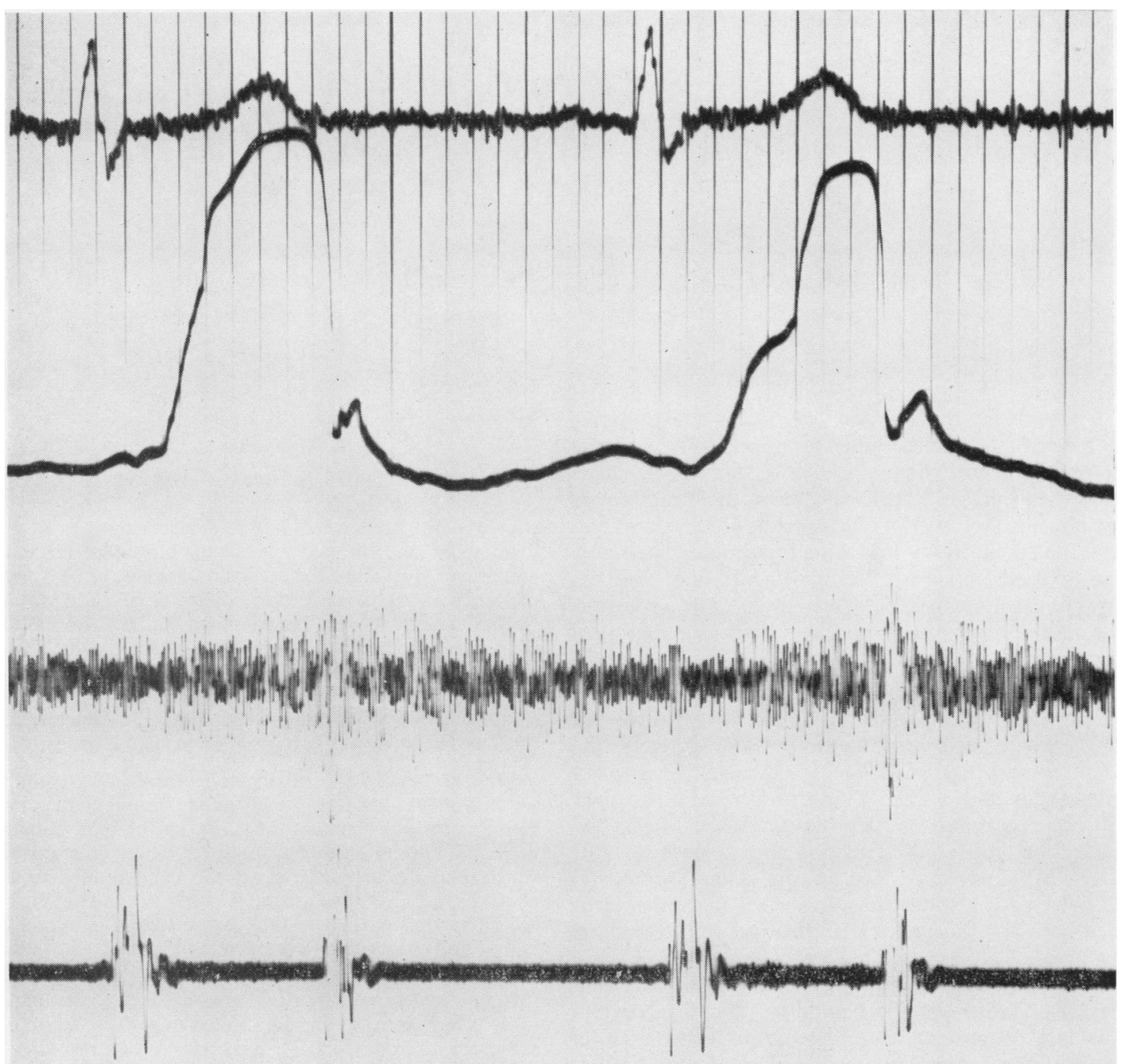

Fig. 1.-Recordings from above downwards are the electrocardiogram, carotid pulse, phonogram over site of aneurysm, and phonocardiogram recorded over apex beat.

[On three occasions during the last 20 years I have heard a localized continuous machinery murmur in the lower part of the chest wall after aspiration of the pleural cavity. The assumption, in these cases, was that traumatic arteriovenous fistulae had been caused by the aspirations. In these three patients the murmur disappeared spontaneously, two within a week, and one within 14 days, and this was explained upon the assumption that spontaneous thrombosis had occurred in the lesions.
The murmur described by Elkington and Howell was caused by an aneurysm upon an intercostal artery; but continuous murmurs in the chest wall can also be caused by collaterals around a coarctation, by distended veins over a retropleural sarcoma, and by haemorrhagic secondaries in ribs. Arteriovenous fistula in the lung and hypernephroma can produce the same effect.-N. R. BARRETT (Editor).] 